\title{
Vacuum freeze-drying of products of goats lactation through heat pump: model development and equipment
}

\author{
Glotova Irina \\ Faculty of Technology and Merchandizing \\ Voronezh State Agrarian University \\ Voronezh, Russia \\ glotova-irina@yandex.ru \\ Shakhov Sergey \\ Limited Liability Company line «SAN» \\ Voronezh, Russia \\ s_shahov@mail.ru \\ PryanishnikovVadim \\ Moguntia-Interrus \\ Moscow, Russia \\ pryanishnikov@moguntia.ru \\ Kurchaeva Elena \\ Faculty of Technology and Merchandizing \\ Voronezh State Agrarian University \\ Voronezh, Russia \\ alena.kurchaeva@yandex.ru
}

\author{
Erofeeva Natalia \\ Faculty of Technology and Merchandizing \\ Voronezh State Agrarian University \\ Voronezh, Russia \\ erofeeva-natalia@rambler.ru \\ Galochkina Nadezhda \\ Faculty of Technology and Merchandizing \\ Voronezh State Agrarian University \\ Voronezh, Russia \\ Galochkina.na@mail.ru \\ Shakhov Artem \\ Limited Liability Company line «SAN» \\ Voronezh, Russia \\ s_shahov@mail.ru \\ Vostroilov Aleksandr \\ The Faculty of Veterinary Medicine \\ and Animal Husbandry Technology \\ Voronezh State Agrarian University \\ Voronezh, Russia \\ kaftchz@ veterin.vsau.ru
}

\begin{abstract}
The task of developing import-substituting technologies for processing and storage of products of goats lactation with relevant equipment should be solved by the following actual reasons: biochemical characteristics as the objects of food nanobiotechnology, the seasonal nature of production of these types of animal products, the variability of the composition and properties depending on various factors, including the stage of lactation. The authors proved expediency of complex use of goat milk and colostrum when developing technologies of natural instant food mixes with the immunomodelling properties and the allergenicity reduced in comparison with natural products of a lactation of cows. For stabilization of biologically active agents, which are peculiar to native raw materials, there is a technology which includes preliminary removal of moisture in the baro-membrane ways. Freezing by cryogenic liquids (liquid nitrogen) and sublimation drying are offered. For ensuring stabilization of biologically active agents as a part of the dehydrated products in the vacuumsublimation dryer, the principle of the thermal pump is used. Installation, in which preservation of native properties of biologically active components as a part of a product is provided,
\end{abstract}

is designed. The design of installation provides removal from a zone of an intensive supply of energy of the dried part of a product due to its destruction as a result of friction about the punched drum surface. Updating an interface of phases and an intensification of process is in addition provided.

Keywords - goat milk, colostrum, vacuum freeze-drying, protein-based, heat pump

\section{INTRODUCTION}

The lactation products of farm animals belong to the most valuable in the biological sense of human nutrition sources, being balanced nutrient sources of natural biologically active substances (BAS) in a wide range of physiological effects [13]. Now the domestic market of dairy products is developing at a dynamic pace. At the same time, the steady tendency to increase the number and production capacity of the farms specializing in the production of goat products is noted. The reasons are related not only to economic efficiency of the 
industry, but also to nutritional value of goat lactation products, possessing unique metabolic and physiological characteristics [4-6].

Biochemical features of products of lactation of goats as objects of food nanobiotechnology, seasonal nature of these types of livestock production, variability of composition and properties depending on various factors, including lactation stages, are connected to a problem of development of importsubstituting technologies of their processing and storage with appropriate technical support [7-8].

The actual problem is to justify the approaches and development of the technology of stabilization of composition and native properties of products of a lactation of goats when in storage, taking into account seasonal nature of production of these types of livestock production and their biochemical features [9-10]. An important task within this problem is to widespread the introduction of sublimation drying in a food production.

The main obstacle for widespread introduction of sublimation drying in the food industry is rather high cost of the received products at the expense of duration and power consumption of process. The solution of the problems connected with elimination of the listed shortcomings is a relevant task.

Reduction of costs of process of vacuum and sublimation dehydration is reached due to use of low-potential power sources, such as own warmth of a product; warmth of the coolant heated in the refrigerator compressor; warmth of the carriers returned in a zone of sublimation; warmth of inert gases and also their combinations taking into account a state and development of the section of phases in a product.

The purpose of the work is to research the process of vacuum and sublimation drying with use of a low-potential power source and improvement on this basis of process and the equipment for his implementation.

\section{OBJECTS AND METHODS OF RESEARCH}

As subjects of a research were lactation products (milk and colostrum) of goats of the Zaanen breed of the period of a milk production of 2014-2015. As subject to comparison used prefabricated whole cow milk with a protein mass fraction of $3.3 \%$ and fat of $3.9 \%$.

Researches of the chemical composition and physicochemical parameters of raw materials and the dehydrated products carried out by the standard and generally accepted methods in research practice.

TABLE I. CHEMICAL COMPOSITION AND DENSITY OF COLOSTRUM AND MILK OF GOATS

\begin{tabular}{|c|c|c|}
\hline \multirow[t]{2}{*}{ Indicators } & \multicolumn{2}{|c|}{ Indicator values } \\
\hline & Colostrum of goats & Milk of goats \\
\hline \multicolumn{3}{|c|}{ Mass fraction, $\%$} \\
\hline lipids & 8.6 & 4.4 \\
\hline Total protein & 8.2 & 3.8 \\
\hline Casein & 3.68 & 2.84 \\
\hline Lactose & 2.94 & 4.6 \\
\hline Ash & 0.99 & 0.85 \\
\hline Density, $\mathrm{g} / \mathrm{cm}^{3}$ & 1.035 & 1.030 \\
\hline
\end{tabular}

The characteristic of objects of a research is presented in table 1 .

Researches of a microstructure of goat and cow milk were carried out on the BIOMED-2 microscope, with a nozzle on the basis of a CANON digital camera, with a 100-time magnification.

When determining content of antioxidants in natural goat and cow milk, milk was stored in standard conditions of low positive temperatures of $(4 \pm 2)^{\circ} \mathrm{C}$.

Comparison of antioxidant activity of two types of dairy raw materials was carried out by the content of antioxidants (CA). Researches were carried out on the device "Tsvetyauza01-AA". The device makes it possible to determine quantitatively relative antioxidant activity of the analyzed samples by measuring the electric current arising by oxidizing of the studied substance (or mixes of substances) on a surface of a working electrode at a certain potential and comparison of his magnitude by a signal of the standard (quercetin) measured in the same conditions.

As object of a research served process of vacuum and sublimation drying of goat colostrum with use of a lowpotential power source. At synthesis of the general model warm and a mass exchange we were based on a condition of balance of energy of sublimation at the front. The boundary condition is a symmetry condition. At synthesis of the general model warm and a mass exchange solved a two-dimensional regional problem which includes non-stationary conditions of heat conductivity, entry and boundary conditions. Required sizes were the temperature fields $t_{1}$ and $t_{2}$ which characterize temperature of a product and the heat-conducting environment in various location of a sublimation drum.

\section{RESULTS AND THEIR DISCUSSION}

Goat milk belongs to the highly nourishing dietary food having the pronounced anti-infectious, antianemic and antihemorrhagic properties. The goats have a much greater genetic variability than cows. It causes a significant variety in the composition of their milk on concentration and physicochemical properties of protein, buffer capacity, mineral content etc. The density of nutrients varies from very small to very high that can be used at creation of various dietary programs for children. In general, goat milk is a source of high-quality protein, fat, vitamins and minerals.

TABLE II. COMPOSITION OF CASEIN FRACTIONS OF GOAT AND COW MILK

\begin{tabular}{|c|c|c|}
\hline \multirow[t]{2}{*}{ Component } & \multicolumn{2}{|c|}{$\begin{array}{l}\text { The content of protein fractions in } \\
\text { different types of milk, \% }\end{array}$} \\
\hline & Goat milk & Cow milk \\
\hline Protein & 3.80 & 3.21 \\
\hline Casein, $\%$ to total protein & 75 & 85 \\
\hline The amount of caseins & 2.84 & 2.52 \\
\hline \multicolumn{3}{|l|}{ including: } \\
\hline$\alpha_{\mathrm{S} 1^{-}}$casein & 0.40 & 0.84 \\
\hline$\alpha_{\mathrm{S} 2-}$ casein & 0.13 & 0.26 \\
\hline$\beta$ - casein & 2.17 & 0.93 \\
\hline$\chi$ - casein & 0.14 & 0.37 \\
\hline$\gamma$ - casein & - & 0.12 \\
\hline
\end{tabular}

Proteins of goat milk significantly differ from proteins of cow milk in both fractional composition, and a spatial 
configuration [8]. The comparative composition of casein fractions of cow and goat milk is presented in table 2 .

It should be noted that goat milk contains twice less $\alpha \mathrm{S} 1$ casein, having allergenic properties. At the same time, the content of $\beta$-casein is 2.3 times higher than that of casein, owing to which goat milk forms a soft clot, easily digested in a stomach of the person. Besides, the most part of whey proteins of goat milk belongs to $\alpha$-lactoalbumine, and cow - to $\beta$ lactoglobulin.

In this regard, goat milk and products of its processing belong to low-alimentary sources of food and do not cause disorders of digestion from the proteolytic fermental system of the human gastrointestinal tract.

Goat and cow milk differ significantly among themselves according to quantitative contents and qualitative composition of fat (Fig. 1). From visible structural elements of milk under a microscope fat globules best identified. In $1 \mathrm{~cm}^{3}$ of their cow milk there are from 2 to 4 billion. Average size of fat globules of goat milk of 2 microns, cow 21.2-31.2 microns. Under a microscope fat globules of natural milk are visible in the form of the light droplets which are strongly refracting light and therefore clearly visible.

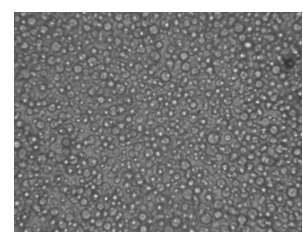

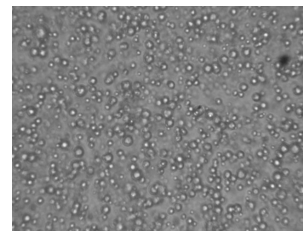

b
Fig. 1. Microstructure of milk, $\times 100$ : a - goat milk; $b-$ cow milk

In fig. 1 it is visible that fat globules of goat milk are smaller, than in the milk of cows, they are more evenly distributed, and are better protected from sticking that provide the larger surface of contact of fat to enzymes of gastrointestinal tract and the best digestibility. Thus, it is possible to say that goat milk the natural homogenized product, due to is digested in a stomach twice quicker than cow. Besides, goat milk is successfully acquired also by small newborns. Products from goat milk can be used as components of a healthy diet for adults for prevention and treatment of chronic diseases of cardiovascular system - a coronary insufficiency, an atherosclerosis, a hypertonia.

Goat milk contains $3.8 \%$ of protein, and $4.4 \%$ of fat while cow's milk - respectively on average $3.3 \%$ and $3.9 \%$. Milk of goats is richer than that of cows in calcium, phosphorus, cobalt and a series of vitamins $\left(\mathrm{B}_{1}, \mathrm{~B}_{2}, \mathrm{C}\right)$. Comparative data on vitamin composition of goat and cow milk are provided in table 3 .

In general, antioxidatic properties of crude products of lactemia of agricultural animals are due to antioxidatic activity of a large number of its components with different chemical nature. In milk raw materials, the main contribution to antioxidizing activity is made by ascorbic acid (vitamin C) and polyphenolums, for example tocopherols (vitamin E), retinol (vitamin A) $[2,3,6]$. Data on the total content of antioxidants in cow and goat milk are given in table 4.
TABLE III. THE VITAMIN COMPOSITION OF GOAT MILK (IN 1 LITER) IN COMPARISON WITH COW MILK (IN BRACKETS THE USDA, US DEPARTMENT OF AGRICULTURE DATA)

\begin{tabular}{|l|c|c|}
\hline Nutrient & Goat milk & Cow milk \\
\hline Vitamin A, ME & $1560(1380)$ & $2074(1850)$ \\
\hline Vitamin D, ME & 33.0 & 23.7 \\
\hline Thiamine, mg & $0.44(0.38)$ & $0.40(0.48)$ \\
\hline Riboflavin, mg & $1.75(1,61)$ & $1.84(1.38)$ \\
\hline Nicotinic acid, mg & $0.94(0.84)$ & $1.87(2.70)$ \\
\hline Pyridoxine, mg & $0,64(0.42)$ & $0.07(0.46)$ \\
\hline Pantothene, mg & $3,46(313)$ & $3.44(3.10)$ \\
\hline Biotin, mg & 0.031 & 0.039 \\
\hline Folic acid, mg & $0.0028(0.005)$ & $0.0024(0.001)$ \\
\hline Vitamin $\mathrm{B}_{12}, \mu \mathrm{g}$ & $0.0043(0.0036)$ & $0.0006(0.00065)$ \\
\hline Ascorbic acid, mg & $21.1(14.7)$ & $15.0(13.0)$ \\
\hline Choline, $\mathrm{mg}$ & 121.0 & 150.0 \\
\hline Inositol, $\mathrm{mg}$ & 110.0 & 210.0 \\
\hline
\end{tabular}

TABLE IV. THE TOTAL CONTENT OF ANTIOXIDANTS IN NATURAL GOAT AND COW MILK

\begin{tabular}{|l|c|c|}
\hline \multirow{2}{*}{$\begin{array}{l}\text { Milk farm } \\
\text { animals }\end{array}$} & \multicolumn{2}{|c|}{\begin{tabular}{l} 
Antioxidants, $\mathbf{~ m g ~ / ~ d m ~}$ \\
\cline { 2 - 3 }
\end{tabular}} \\
$\begin{array}{l}\text { On the 2nd day of } \\
\text { storage }\end{array}$ & $\begin{array}{l}\text { On the 4th day of } \\
\text { storage }\end{array}$ \\
\hline Goat & 7.0 & 2.2 \\
\hline Cow & 2.5 & 0.5 \\
\hline
\end{tabular}

Determination of content of antioxidants of milk allows stating that natural goat milk has higher antioxidant properties in comparison with those of cow's milk and, as a product, the increased food and biological value, which researches are necessary for development of new dairy products - a source of natural BAS - with the increased storage capacity.

A more concentrated form of alimentary and biologically active substances is the colostrum produced in the first days of lactation [2, 4]. A colostrum differs from mature milk of goats by appearance, chemical composition, physiological action. It has dense, viscous consistence, yellow-white color, saltish by taste, with specific smell, high acidity, there is a lot of vitamins (A, B, C, D, E). It differs from milk by a high content of magnesium. The highest mass fraction of fat in comparison with other species of agricultural animals is characteristic of a goat colostrum. Immunoglobulins are its part $(\mathrm{IgA}, \mathrm{IgG}, \mathrm{IgD}$, $\operatorname{IgE}, \operatorname{IgM}) ; 90 \%$ of them fall to the share of IGA. The cytokines provide intercellular interaction in the immune system (for example, interferon). Growth factors (epithelial, insulinoid, platelet, transforming, etc.) stimulate the growth of various tissues. Lactoferrin, interfering with reproduction of microorganisms, strengthens phagocytosis and efficiency of cytokines. There are factors of nonspecific immunity (lysozyme, etc.), amino acids (a proline - important for regulatory peptides of the immune system, the taurine is necessary for development of brain); high-assimilable proteins, fats, carbohydrates, vitamins (A, $\beta$-carotene, $\mathrm{E}, \mathrm{B}_{12}$, D), minerals. On albuminous composition a colostrum is closer to a blood, than milk as in a colostrum there are a lot of such proteins as globulins and albumins.

Colostrum contains enzymes, xanthine oxidase, lactoperoxidase, which at the cellular level increase the intake of glucose and amino acids.

Colostrum shows antioxidant properties in connection with existence of tocopherols and lactoferrin - iron chelator. 
Connecting iron, lactoferrin interferes with development of chain reactions of the peroxidation oxidation of lipids (POL).

Colostrum renders expressed immunoprotection (especially concerning infections of mucous digestive tract, the respiratory system), immunoregulation in case of autoimmune diseases and allergic conditions, protecting and restoring mucous digestive tract, nutritious and regeneration, rejuvenating action. Products on its basis are recommended during high physical and mental stresses, immunodeficiencies, various autoimmune diseases, irritable bowel syndrome, in cosmetic programs for prophylaxis of age changes, etc.

Products of colostrum processing can be effective when used both for the general improvement of the population and in the rehabilitation plan of people who come under influence of chronic radiation exposure. It can happen to people who live in the territory, polluted by radionuclides and the staff of the NPP and other industrial facilities, connected with processing and storage of radioactive substances. Products of processing of colostrum can find application with the preventive purpose during organization of preventive foods of working various chemical enterprises and also for improvement of the population and stimulation of adaptation processes in an organism and, especially, for the correcting baby food. It is used most technologically in the form of a freeze-dried (lyophilized) product.

The seasonal nature of goats' lactation food production, in particular, colostrum, the variability of composition and properties, depending on different factors, including stage of lactation, are quite relevant to the development of modern technologies of its processing and storage with relevant technical equipment and software technical documentation.

The most effective method of preserving colostrum is freeze-drying as this product contains immune factors, growing hormones, vitamins, enzymes and other substances, collapsing under high temperatures.

In the development of new products technologies with reduced allergenicity, it is required to investigate the effect of freezing, freeze-drying conditions of storage of goats colostrum on its quality.

In this case, freeze-dehydration as a method of stabilizing the quality of biological systems is the one of the most promising methods of dehydration with obtaining instant products, preserving the original level of activity of biologically active substances.

The authors have proposed technology-based product colostrum and goat milk, which includes the preliminary removal of moisture baromembrane methods, freezing cryogenic fluids (liquid nitrogen) and freeze-drying. The creation of such products in dry form requires extensive fundamental and applied research of intense dehydration processes by biologically active products based on vacuumsublimation drying. The development of technology for dry biologically active products and development of equipment for its implementation was carried out by the principle of a heat pump that will significantly reduce energy consumption and preserve the native properties of the product.
Freeze-dehydration as a method of stabilization of the quality indicators of the biological system was chosen due to the fact that this method can almost completely (95\%) preserve the foods nutrients, vitamins, minerals, original shape, natural scent, taste and color. That is one of the major advantages of sublimation, it allows one to avoid the decomposition of the product structure, to restore quickly the freeze-dried products, as they have a porous structure. This fact is notable in that sublime products are fully suitable for children and dietary food.

Products of freeze drying have tremendous opportunities for use as instant food and semi-finished products for further industrial processing (confectionery, disconcert, meat and dairy, perfumery and other industries). The freeze-dried products received popularity in the technologies of production of medicines, ferments, enzymes, herbal extracts and other rather costly objects, when one wants to ensure the safety of the dry object that can be useful in the raw form for a long time.

For implementing the technology of obtaining biologically active products and justifying the use of the principle of the heat pump in a vacuum freeze-dryer, an installation was designed (Fig. 2). It ensures the preservation of the native biologically active properties of the product as the design of the installation involves removing the dried portion of the product from the zone of intense release of energy.

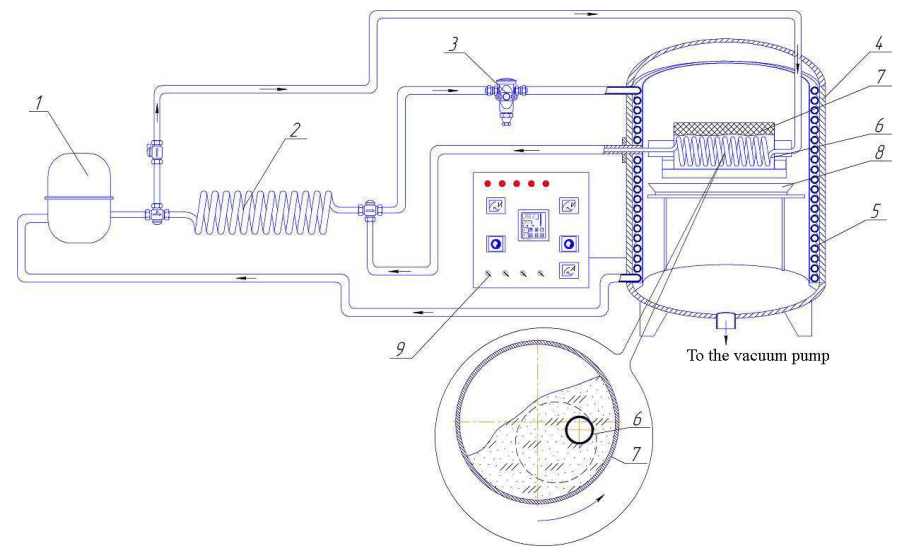

Fig. 2. Vacuum-sublimation unit: 1 - compressor of the refrigerating machine; 2 - condenser; 3 - thermostatic expansion valve; 4 - dryer housing; 5 - desublimator; 6 - heat transfer device; 7 - drum; 8 - pallet; 9 - control panel

A dry part of the product is destroyed due to friction against a perforated surface of the drum. Then the dry particles slip through its perforated surface. This solution keeps the interface of phases and thus allows one to intensify the process.

The authors have carried out the simulation of the process of freeze dehydration of goat colostrum. In describing this process, it was assumed that the sublimation of ice in a drying installation is carried out inside the drum of a certain length, which is considered as the constant and is denoted by parameter $L$. In the layer of the product, there was a heating element in a coil. It had a cross-sectional shape of the segment. Inside it there was coolant. The authors have designated the cross-sectional area of the product together 
with the tube, located in the product as constant $S$, and the width of the surface of the product as $L_{l}$.(Fig. 3).

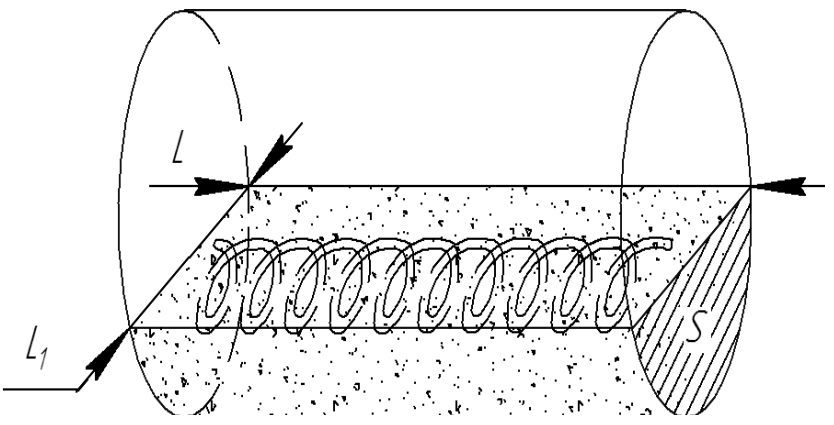

Fig. 3. Drum of the dryer with a layer of a disperse product

The frozen granular product is constantly mixed and moved along the drum at a constant speed. During the steady process is heat exchange between the product and heat carrier, passing with a constant speed through the coil. The product, receiving thermal energy and falling on the surface, is subjected to a sublimation process (dehydration), and coolant is subjected to cooling.

To simplify the calculations and mathematical model, the authors considered a cylinder with cross sectional area equal to $\mathrm{S}$ with radius $R_{2}$. Since the cross section of the coil is oval, the authors designated $R_{1}$ as the radius of the circle with the same area, which is segment. They got two cylinders, one inside the other with a common longitudinal axis. The inner cylinder represents the area of the coolant (refrigerant), and the outer cylinder represents the area of the product (Fig. 4).
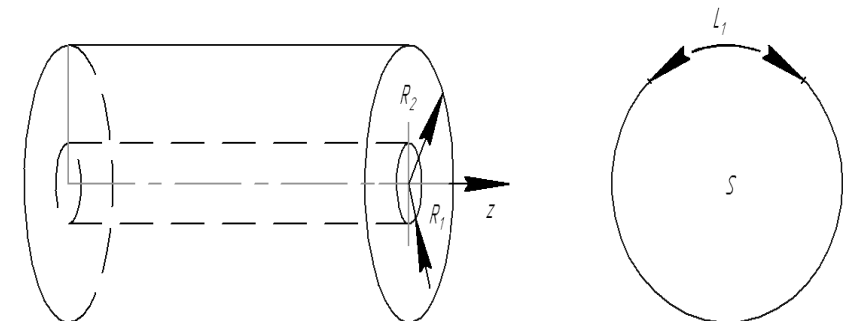

Fig. 4. Simplified scheme of the dryer drum

Because the sublimation process occurs at a certain limited surface of the product, the authors have introduced the ratio of the real area of sublimation to the area of the lateral surface of the obtained cylinder

$$
G=\frac{L_{1}}{L_{2}}
$$

where $L_{1}$ - the width of the product surface in the drum, and $L_{2}$ is the length of the circumference of the constructed cylinder.

Denoting the intensity of sublimation through $q_{m}$, one got the real intensity of the sublimation process with the relations of areas:

$$
q_{m}^{\prime}=G \cdot q_{m}
$$

$$
q_{m}=\alpha_{m p}\left(p_{H}-p_{S}\right) \cdot \frac{{ }_{0}}{B},
$$

here $q_{m}$ - the intensity of sublimation in obtained cylindrical model, $\mathrm{kg} /\left(\mathrm{m}^{2} \cdot \mathrm{s}\right) ; q_{m}^{\prime}-$ the real intensity of sublimation, $\mathrm{kg} /\left(\mathrm{m}^{2} \cdot \mathrm{s}\right) ; \alpha_{m p}-$ the coefficient of heat-mass transfer at normal pressure, $\mathrm{kg} /\left(\mathrm{m}^{2} \cdot \mathrm{s} \cdot \mathrm{Pa}\right) ; p_{s}-$ the saturated vapour pressure at the surface temperature of product, $\mathrm{Pa}$,

$$
p_{s}=p_{v}\left(\left.t_{2}\right|_{r=R_{2}}\right) \text {, }
$$

where $p_{v}$ - the vapor pressure in the chamber, $\mathrm{Pa} ; B_{0}-$ normal pressure, $\mathrm{\kappa Pa}\left(B_{0}=101,3\right.$ кPa (760 Mm Hg. Art.)); $B-$ the barometric pressure in the chamber, $к \mathrm{~Pa}$.

The heat transfer process occurs in a closed mode. That is why the environment that brings the heat is cooled over time and, taking into account the displacement and the product, thus receives heat energy. This is reflected in the dependence of the temperature of the product and heat carrier depending on time and spatial coordinates:

$$
t=t(r, \tau)
$$

Taking into account the geometric shape of the obtained physical model, the authors considered a cylindrical coordinate system by placing the origin at the center and the beginning of the cylinder. Considering the earlier assumptions, mathematical formulation of the problem resembles the following:

$$
\begin{gathered}
c_{1} \rho_{1} \frac{\partial t_{1}}{\partial \tau}=\frac{1}{r} \frac{\partial}{\partial r}\left(\lambda_{1} r \frac{\partial t_{1}}{\partial r}\right), 0<r<R_{1}, \quad \tau>0, \\
c_{2} \rho_{2} \frac{\partial t_{2}}{\partial \tau}=\frac{1}{r} \frac{\partial}{\partial r}\left(\lambda_{2} r \frac{\partial t_{2}}{\partial r}\right), R_{1}<r<R_{2}, \tau>0, \\
t_{1}(r, 0)=c o n s t=t_{1,0}, \\
t_{2}(r, 0)=\text { const }=t_{2,0}, \\
\frac{\partial t_{1}(0, \tau)}{\partial r}=0 \\
-\left.\lambda_{1} \frac{\partial t_{1}}{\partial r}\right|_{r=R_{1}}=\alpha_{1}\left(\left.t_{1}\right|_{r=R_{1}}-\left.t_{2}\right|_{r=R_{1}}\right) \\
-\left.\lambda_{2} \frac{\partial t_{2}}{\partial r}\right|_{r=R_{1}}=\alpha_{1}\left(\left.t_{1}\right|_{r=R_{1}}-\left.t_{2}\right|_{r=R_{1}}\right) \\
\left.\lambda \frac{\partial t{ }_{2}}{\partial r}\right|_{r=R}=\gamma \quad{ }_{s u b m}^{q^{\prime}}+\alpha_{2}\left(\left.t_{2}\right|_{r=R_{2}} e n v\right),
\end{gathered}
$$

where $t_{1}(r, \tau), t_{2}(r, \tau)$ - the temperature field of a heat carrier and product, respectively, $\mathrm{K} ; c_{1}(t), c_{2}(t)$ - the heat capacity of the carrier and product, respectively, $\mathrm{J} / \mathrm{kg} \cdot \mathrm{K} ; \rho_{1}, \rho_{2}-$ the density of the carrier and product, respectively, $\mathrm{kg} / \mathrm{m}^{3} ; \lambda_{1}(t)$, $\lambda_{2}(t)-$ the coefficients of heat conductivity of the carrier and 
product, respectively, $\mathrm{W} / \mathrm{m} \cdot \mathrm{K} ; t_{\text {env }}$ - the temperature of the environment, $\mathrm{K} ; \gamma_{\text {sub }}$ - the heat of sublimation, $\mathrm{J} / \mathrm{kg} ; R_{1}-$ the external radius of the heat medium and the boundaries of contact with the product, $\mathrm{m} ; R_{2}-$ the external radius of the product, $\mathrm{m} ; \tau$ - time, $\mathrm{s} ; r$ - spatial coordinate, $\mathrm{m}$.

The task (6) - (13) is a two-dimensional boundary value problem. It includes the unsteady heat equation (6), (7), the initial conditions (8) and (9), boundary conditions (10) - (13). The sought quantities are temperature fields $t_{1}, t_{2}$.

Boundary condition (10) is the condition of symmetry, and conditions (11), (12) are the conditions of conjugation at the interface of two media. Equation (13) is the condition for the energy balance at the front of sublimation.

In this model, the main part is the temperature of the product and the environment not at different time but in different position of the sublimation drum, because the environment moves through the coil and gives off heat and cools. The product moves from one side of the drum to the other, receives energy and dries. Therefore, it is possible to regulate the speed of the product and the carrier for a stronger cooling of the environment, better dehydration of the product, to reduce energy consumption and to increase the productivity of the apparatus.

For this purpose, the authors made the transition from from the time parameter to the parameter of the longitudinal axis of the cylinder $\tau \rightarrow z$, i.e. $t_{1}=t_{1}(r, z)$ and $t_{2}=t_{2}(r, z)$.

Let $\vartheta_{1}$ be the speed of the medium in a horizontal channel and not in the actual coil, and $\vartheta_{2}$ be the speed of longitudinal displacement of product particles. Then $\tau=\frac{Z}{\vartheta_{k}}$, where $\mathrm{k}=1$, 2. Therefore, equations (6), (7), (10) take the following form:

$$
\begin{gathered}
c_{1} \rho_{1} \vartheta_{1} \frac{\partial t_{1}}{\partial z}=\frac{1}{r} \frac{\partial}{\partial r}\left(\lambda_{1} r \frac{\partial t_{1}}{\partial r}\right), 0<r<R_{1}, \quad z>0, \\
c_{2} \rho_{2} \vartheta_{2} \frac{\partial t_{2}}{\partial z}=\frac{1}{r} \frac{\partial}{\partial r}\left(\lambda_{2} r \frac{\partial t_{2}}{\partial r}\right), R_{1}<r<R_{2}, \quad z>0, \\
\frac{\partial t_{1}(0, z)}{\partial r}=0,
\end{gathered}
$$

In order to judge the effectiveness of the sublimation process, it is necessary to find the moisture content of the product at different points in time (at different points of the drum). Because the product is constantly mixed and the freeze-drying process is only on the surface, then let us consider that the moisture content of the product is not dependent on the radius of the layer $u \neq u(r)$, where $u$ - the moisture content of product, $\mathrm{kg} / \mathrm{kg}_{\text {dry matter }}$.

For humidity calculations, the authors have divided the drum on the very thin cross layers (Fig. 5) and assumed that the moisture content within each layer is the same due to its very small thickness, $l \rightarrow 0$.

$$
u_{i}=u\left(\tau_{i}\right)
$$

where $u_{i}$ - the moisture content at the time moment $\tau_{i}$,

$$
\begin{aligned}
& u_{i+1}=u\left(\tau_{i}+\Delta \tau\right), \\
& u_{i+1}=u_{i}-\Delta u,
\end{aligned}
$$

$m_{B i}=\rho_{0} V^{*} u_{i}-$ the mass of moisture at the time moment $\tau_{i}$, $\rho_{0}-$ the density of absolutely dry product, $\mathrm{kg}_{\text {dry matter. } /} \mathrm{m}^{3}$

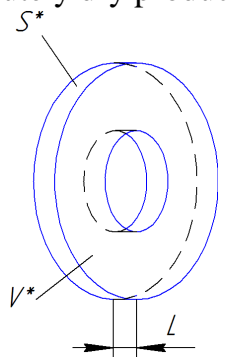

Fig. 5. Lateral layers of a drum of thickness $1: \mathrm{V} *$ - the volume of the product in the layer, $\mathrm{S} *$ - the area of the outer surface of the layer sign)

Then the mass of the evaporated moisture (has a negative

$$
\begin{gathered}
\Delta m_{B}=-q_{m}^{\prime} \cdot \Delta \tau \cdot S^{*}=-q_{m}^{\prime} \cdot \Delta \tau \cdot l \cdot 2 \pi \cdot R_{2}, \\
m_{B i+1}=m_{B i}+\Delta m_{B}=\rho_{0} V^{*} U_{i}-q_{m}^{\prime} \cdot \Delta \tau \cdot l \cdot 2 \pi \cdot R_{2}, \\
\text { transition from mass to moisture content } m_{B i+1} \rightarrow u_{i+1} \\
V^{*}=l \pi\left(R_{2}^{2}-R_{1}^{2}\right), \\
u_{i+1}=\frac{\rho_{0} V_{i}^{*} u_{i}-q_{m}^{\prime} \cdot \Delta \tau \cdot l \cdot 2 \pi \cdot R_{2}}{\rho_{0} V^{*}}=u_{i}-\frac{q_{m}^{\prime} \cdot \Delta \tau \cdot l \cdot 2 \pi \cdot R_{2}}{l \pi \cdot\left(R_{2}^{2}-R_{1}^{2}\right)}=u_{i} \frac{\frac{2 q_{m}^{\prime} \cdot \Delta \tau \cdot R_{2}}{R_{2}^{2}-R_{1}^{2}}}{}
\end{gathered}
$$

If you go from a time coordinate to the spatial coordinates, then $\Delta \tau=\frac{h}{\vartheta_{2}}$, where $h$ is the step on the axis $Z$.

Then (18) takes the form:

$$
u_{i+1}=u_{i}-\frac{2 q_{m}^{\prime} \cdot h \cdot R_{2}}{\vartheta_{2}\left(R_{2}^{2}-R_{1}^{2}\right)}
$$

Since $q_{m}^{\prime}=q_{m}^{\prime}\left(t_{2}\right)$ it is necessary to calculate the field of temperatures on the outer layer to determine the moisture content of the product in different parts of the drum. To this end we implemented a decision system: $\left(6^{*}\right),(7 *),(8),(9)$, $(10 *),(11)-(13)$.

With the aim to confirm the model representation of the mechanism of dehumidification of the granules from the frozen colostrum sublimation, the authors have designed and constructed a pilot model of the device for vacuumsublimation dehydration using low-grade heat of the hot refrigerant (see fig. 2). In this case, energy supply was carried out by a refrigerating agent, heated in the compressor of the refrigerating machine, which contributed to significant energy 
saving compared to traditional plants, which, in most cases, use conductive or radiative supply of energy.

The pilot plant works as follows. Compressed to high pressure and temperature refrigerant from the compressor of refrigerating machine 1 is sent to heat transfer device 6 , in which the transfer of heat to the product occurs. Due to this process, there is the sublimation of moisture, which settles on tubes desublimator 5. The desublimator is cooled by evaporation of the refrigerant in the compressor, taken away from compressor 1 .

In the initial moment of time, the refrigerant goes through the condenser 2 , after passing the heat transfer device 6 the refrigerant condenseries it to a liquid state, by cooling the granules of the frozen product. Then the refrigerant is directed into the tubes of desublimator 5, bypassing the condenser 2 . Thus, in the future, one can unsubscribe from the operation of capacitor 2, using the heat of the hot refrigerant for the purpose of dehydration. For cooling the desublimator, it is advisable to use the condensed refrigerant from heat transfer device 6 , which will reduce the cost of the drying process.

In a pilot plant, studies have been conducted and the curves of the kinetics of the process of freeze dehydration of goat colostrum were obtained (fig. 6).

As a result of model experiments, the adequacy to the offered mathematical model, which does not exceed $12 \%$, has been confirmed. The mathematical model was tested for adequacy, the divergence between experimental and theoretical data does not exceed $12 \%$.

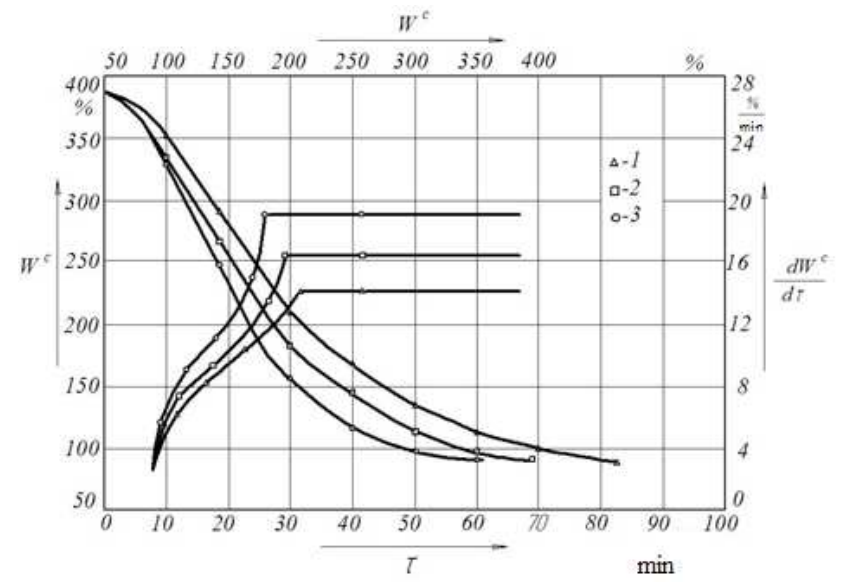

Fig. 6. Kinetics of drying goat colostrum with different heating temperature, ${ }^{\circ} \mathrm{C}: \Delta-1-40 ; \square-2$ - 30; ०-3 - 20 caption

From Fig. 6 it can be seen that with increasing heating temperature, the drying time decreases. However, a further increase in the temperature of the product, which contains immune factors, growth hormones, vitamins, enzymes and other thermolabile substances leads to their destruction under the influence of high temperatures. By the nature of curves, one can judge a slight decrease of the period of falling drying rate with the increase in temperature and more heating the product at the end of the drying process.

\section{CONCLUSIONS}

To implement the technology implementation of obtaining biologically active products and to justify the use of the principle of the heat pump in a vacuum freeze-dryer, an installation was designed. It ensures the preservation of the native biologically active properties of the product as the design of the installation involves removing the dried portion of the product from the zone of intense release of energy. The dry part of the product is destroyed due to friction against a perforated surface of the drum. Then the dry particles slip through its perforated surface. This solution preserves the interface of phases and thus allows one to intensify the process.

The authors found that that the experimental setup that implements the technology of vacuum freeze-dehydration of lactation goat's products provides a residual moisture content of the product of no more than $3 \%$. This ensures stability of the product quality when stored at a relative humidity of no more than $70 \%$ and temperature, not exceeding $25^{\circ} \mathrm{C}$ during 12 months while maintaining the biological activity of incoming components. The properties of colostrum as an immune-modulating natural raw material source is promising for the development of formulations of a lyophilized protein blends combination.

\section{References}

[1] A. Loste, J.J. Ramos, A. Fernandez, L.M. Ferrer, D. Lacasta, M.T. Verde, M.C. Marca, A. Ortan,"Effect of colostrum treated by heat on immunological parameters in newborn lambs", Livestock Science, Vol. 117, Issues 23, pp. 176-183, September 2008.

[2] I. Moreno-Indias, D. Snchez-Macas, N. Castro, A. Morales-delaNuez, L.E. Hernndez-Castellano, J. Capote, A. Argello,"Chemical composition and immune status of dairy goat colostrum fractions during the first $10 \mathrm{~h}$ after partum ”, Small Ruminant Research, vol.103, Issues 23, pp. 220224, April 2012.

[3] A.C. Alves, N.G. Alves, I.J. Ascari, F.B. Junqueira, A.S. Coutinho, R.R. Lima, J.R.O. Porez, S.O. De Paula, I.F. Furusho-Garcia, L.R. Abreu,"Colostrum composition of Santa Inos sheep and passive transfer of immunity to lambs", Journal of Dairy Science, vol. 98, Issue 6, pp. 3706-3716, June 2015.

[4] Agus Bahar Rachmana, Rarah RA Maheswarib , Mirnawati S Bachroem "Composition and Isolation of Lactoferrin from Colostrum and Milk of Various Goat Breeds", Procedia Food Science, vol. 3, pp. 200 - 210, 2015

[5] M. Marounek1 , L. Pavlata , L. Mišurová , Z. Volek1 , R. Dvořák "Changes in the composition of goat colostrum and milk fatty acids during the first month of lactation", Czech J. Anim, vol. 57, pp.28-33, 2012.

[6] N. M. A. Mahmoud, I. E. M. Zubeir, A. A. Fadlelmoula "Colostrum composition and performance of Damascus goats raised under Sudan conditions", Wudpecker Journal of Agricultural Research, vol. 1(8), pp. $341-345,2012$

[7] V.Ye. Dobromirov, S.V. Shakhov, T.I. Nekrylova, S.A. Bokadarov, "Exergetic analysis of the vacuum-sublimation installation", Vestnik of International Academy of Refrigeration, vol. 4, pp 46-48, 2011.

[8] I.A. Glotova, N.A. Yerofeyeva, A.S. Shakhov, "Use of goat lactation products in the manufacture of natural proteins based for fast-soluble food mixtures", The scientific journal NRU ITMO. a series of "Processes and devices of food manufactures", vol. 3, pp. 71-80, 2015.

[9] L. Hodulová, L. Vorlová, R. Kostrhounová "Dynamical changes of basic chemical indicators and significant lipophilic vitamins in caprine colostrum", ACTA VET. BRNO, pp. 15-19, 2014. 
[10] N. Zaharia1 , R. Salamon , C. Pascal1 , S. Salamon , R. Zaharia "Changes in fatty acid composition and cholesterol content of goat colostrum", Biotechnology in Animal Husbandry", vol. 27 (3), pp. 12011208,2011

[11] A.A. Barresi, R. Pisano, D. Fissore et al., "Monitoring of the primary drying of a lyophilization process in vials" ,Chemical Engineering and Processing: Process Intensification, vol. 48, no. 1, pp. 408-423, 2009.
[12] Fissore D, Pisano R, Barresi A.A, "Model-based framework to optimize pharmaceuticals freeze drying", Drying Technology, vol. 9, pp. 946958, 2012.

[13] H.Cheng, S.Tsai, C. Cheng "Analysis of heat transfer mechanism for shelf vacuum freeze-drying equipment" Advances in Materials Science and Engineering, 2014 Article ID 515180, DOI: 10.1155/2014/515180. 